ECOLOGICA, Vol. 28, No 103 (2021), 395-402

https://doi.org/10.18485/ecologica.2021.28.103.9

Originalni naučni rad

UDC: [316.422.42:502.174.3]:616-036.21

\title{
Značaj socijalne prihvaćenosti obnovljivih izvora energije za realizaciju ciljeva održivog razvoja u periodu pandemije
}

\section{The importance of social acceptance of renewable energy sources for the realization of sustainable development goals in the pandemic period}

\author{
Milovan Vuković1 ${ }^{*}$, Njegoš Dragović ${ }^{2}$, Nada Štrbac ${ }^{3}$, Aleksandra Vuković ${ }^{4}$ \\ 1,2,3Univerzitet u Beogradu, Tehnički fakultet u Boru, V.J. 12, 19210 Bor, Srbija / \\ University of Belgrade, Technical Faculty in Bor, V.J. 12, 19210 Bor, Serbia \\ ${ }^{4}$ Akademija tehničko-umetničkih strukovnih studija; Odsek: Visoka železnička škola, Z. Čelara 14, 11000 \\ Beograd, Srbija / \\ Academy of Technical and Artistic Vocational Studies; Department: Railway High School, Z. Čelara 14, \\ 11000, Belgrade, Serbia
}

${ }^{*}$ Autor za prepisku / Corresponding author

Rad primljen / Received: 18.12.2020, Rad prihvaćen / Accepted: 12.08.2021.

Sažetak: Ciljevi održivog razvoja su univerzalni poziv za iskorenjivanje siromaštva, zaštitu životne sredine i obezbeđivanje mira i prosperiteta za sve. Među 17 ciljeva održivog razvoja posebno se ističe primena dostupne i obnovljive energije koja u periodu društvenih kriza može doprineti smanjenju energetske zavisnosti i energetskih hazarda, zagađenja vazduha i štetnih efekata na ljudsko zdravlje. Korišćenje obnovljivih izvora energije (OIE) za proizvodnju električne ili toplotne energije može da smanji potrošnju nafte, benzina ili gasa,kao i potrebu za uvećanjem broja termoelektrana, što povoljno utiče na smanjenje zagađenja vazduha i predstavlja doprinos rešenju problema klimatskih promena. U radu su razmatrane dimenzije socijalne prihvaćenosti OIE: pre svega na osnovu analize projekata u oblasti primene geotermalnih resursa. Uticaj tržišta, socio-političke i lokalne sfere prepoznaju se kao važni činioci prihvaćenosti, kako bi projekti korišćenja geotermalnih voda zadovoljili energetske potrebe.

Ključne reči: obnovljivi izvori energije, projekti, geotermalna energija, socijalna prihvaćenost,održivi razvoj.

\begin{abstract}
The Sustainable Development Goals are a universal call to eradicate poverty, protect the environment and ensure peace and prosperity for all. Of the 17 goals of sustainable development, special emphasis is placed on available and renewable energy, which in the period of social crisis can contribute to the reduction of energy hazards, harmful effects on air pollution and human health. Renewable energy sources (RES), used for the production of electricity or heat, can decrease of oil, gasoline or gas consumption, as well as the need for new thermal power plants, which reduces the effects of pollution. The paper considers the dimensions of RES acceptance on the basis of analyses of projects directed to the use geothermal resources. The influence of the market, socio-political and local spheres are recognized as important factors of acceptance, in order for geothermal exploitation projects to meet energy needs.
\end{abstract}

Keywords: renewable energy sources, projects, geothermal energy, social acceptance, sustainable development.

\footnotetext{
${ }^{1}$ orcid.org/0000-0003-1715-1078, e-mail: mvukovic@tfbor.bg.ac.rs

${ }^{2}$ orcid.org/0000-0003-3634-4545, e-mail: njegdr@gmail.com

${ }^{3}$ orcid.org/0000-0003-4836-1350, e-mail: nstrbac@tfbor.bg.ac.rs

4orcid.org/0000-0003-4864-2080, e-mail: dr.milovanvukovic@yahoo.com
} 


\section{UVOD / INTRODUCTION}

Obnovljivi izvori energije (OIE) predstavljaju značajan resurs koji može da poboljša kvalitet života ljudi i životne sredine. Ciljevi održivog razvoja obavezuju sve države da primene različite mere. „Dostupna i obnovljiva energija“ prepoznaje se kao poželjan način da se proizvede toplotna i električna energija bez mogućnosti da negativno utiče na klimatske promene i ljudsko zdravlje . U 2011.godini iz OIE dobijeno je više od $20 \%$ proizvedene električne energije u svetu. Kada se zna da više od petine svetske populacije nema struju, te da stalno raste tražnja za njom,realno je očekivanje da se jaz prevaziđe većim ulaganjima u obnovljivu energiju. Snabdevanje tzv. Zelenom energijom do 2030. godine trebalo bi da uključi investicije u čiste energente poput energije sunca, vetra, biomase, pa i geotermalnih izvora kojima se ne pridaje dovoljno pažnje (UNDP). Početna faza svakog projekta ovog tipa je istraživanje potencijalnog ležišta, a u slučaju geotermalnih voda postoje osobenosti povezane sa prisustvom različitih izvora neodređenosti koje nije lako izraziti u kvantitativnom smislu. Izdvajaju se u ovom slučaju tri izvora neodređenosti: geološki, tehnološki i ekonomski. Viter i saradnici ukazuju na potrebu razlikovanja objektivne od subjektivne neodređenosti (Witter et al., 2019). Geotermalna energija bi trebalo da predstavlja deo dugoročne strategije u obezbeđenju električne energije u zemljama koje raspolažu ovim resursima (Gerhinger \& Loksha, 2012). Rezultati svojevremeno sprovedenih istraživanja na prostorima Australije potvrđuju pretpostavku o pozitivnim socijalnim efektima lokalnih projekata u oblasti OIE (Hicks \& Ison, 2011). Slična istraživanja (2009) u Španiji ukazuju na značajan efekat na planu povećanja zaposlenosti, po čemu se izdvajaju projekti korišćenja biogoriva (Del Rio \& Burgullio, 2009).

Projekti OIE koji vode brigu o lokalnim potrebama naglašavaju visok stepen učešća ljudi iz lokalne zajednice u odlučivanju, planiranju i implementaciji određenog projekta i, drugo, koristi definišu na način da ih osete građani na lokalu u što većoj meri (Šahović \& Pereira da Silva, 2016). U ulozi vlasnika koji nadziru realizaciju projekata OIE u Nemačkoj pojavljuju se pojedinci, lokalne zajednice i kooperative (Hall et al., 2016). Nemačka je postavila cilj da do 2030. godine poveća učešće OIE u ukupnoj potrošnji energije na $50 \%$, koje bi u narednim dekadama trebalo da iznosi 60\% u 2040 i 80\% 2050. godine (Câmpeanu \& Pencea, 2014).

Kooperativni model vlasništva, čini se, daje najbolje efekte, posebno kada se radi o projektima za solarnu energiju i energiju vetra. Dobri primeri u praksi po pitanju kooperativa su zabeleženi kod korišćenja biomase u Austriji i severnoj Italiji (Viardot,
2013). Veće učešće građana, participativno odlučivanje i odgovarajuća raspodela dobiti, kako pokazuju novija istraživanja, dovodi do smanjenja otpora građana u lokalnim zajednicama kada je, na primer, o energiji vetra reč (Musall \& Kuik, 2011). Meštani odobravaju postavljanje vetrogeneratora ukoliko su manje snage (Warren \& McFadyen, 2010).

Lokalno protivljenje prema projektima iz domena OIE, kao i mnoštvu situacija u oblasti upravljanja životnom sredinom, najčešće se opisuje sindromom NIMBY (Not in my back jard). Pretpostavka je da ljudi koji stanuju u blizini nekog postrojenja imaju drugačije percepcije, odnosno negativnije stavove o dobiti od korišćenja određenih obnovljivih izvora energije (Devine-Wright, 2011). Radikalnija verzija sindroma NIMBY izražava se akronimom NOPE (Not on planet Earth). Ne postoje ipak čvrsti empirijski dokazi koji bi potvrdili hipotezu o sindromu NIMBY kada se on odnosi na OIE (Bidvell, 2013). Posebno se to odnosi na stavove prema korišćenju energije vetra (Wolsink, 2000). Tzv. NIMBY sindrom je istraživan i sa stanovišta geotermalnih resursa (Polyzou \& Stamataki, 2010).

U središtu istraživanja, čiji su rezultati izloženi u ovom radu, nalaze se pitanja socijalne prihvaćenosti geotermalnih OIE i to geotermalnih voda. Geotermalni energetski resursi, uprkos obilju ovih izvora na teritoriji Republike Srbije, nedovoljno se koriste. Nedavna iskustva u realizaciji projekata dobijanja energije iz ostalih OIE - naročito u vreme pandemije (na primer, problematika malih hidroelektrana, MHE) mogla bi biti od koristi u analizi socijalne prihvaćenosti geotermalnih voda.

\section{SOCIJALNA PRIHVAĆENOST OIE / SOCIAL ACCEPTANCE OF RES}

$U$ većini novijih studija o primeni OIE naglašava se važnost socijalne prihvaćenosti (Social Acceptance, SA) u cilju usvajanja i realizacije ovih projekata. Ovo polje istraživanja zauzima prostor između dve razvijenije oblasti istraživanja koje se bave fenomenima tehnoloških promena i njihovom difuzijom, s jedne, i socijalnim aspektima energije i energetske politike, s druge strane (Gaede \& Rowlands, 2018). Koncept socijalne prihvaćenosti uglavnom se odnosi na poželjan ili pozitivan odgovor pripadnika zajednice (počev od države ili regiona, preko jedinica lokalne samouprave, do nivoa domaćinstva ili organizacije) u vezi sa predloženom ili postojećom tehnologijom ili socio-ekonomskim sistemom (Upham et al., 2015). Da bi se došlo do socijalne prihvaćenosti neophodno je delovati u pravcu: smanjenja štetnih efekata na životnu sredinu i sprečavanja štetnih posledica po ljudsko zdravlje kao i stvaranja koristi za lokalno stanovništvo. Ovi preduslovi se nesumnjivo pojavljuju 
kao opterećenje prilikom sastavljanja budžeta budući da treba ugraditi i eksterne troškove u projekat koji je predmet analize.

U socijalnu prihvaćenost, kao delu strategije za implementaciju tehnologija korišćenja OIE, nije se sumnjalo budući da su rezultati mnogih ispitivanja javnog mnjenja išli u prilog takvom uverenju. Posebno se to odnosilo na širenje postrojenja za korišćenje energije vetra. Za aktere koji učestvuju u razvoju OIE (investitore, vlasti, energetske kompanije i privatne lokalne investitore) ovaj problem nije postojao (Wustenhagen et al., 2007). Ubrzo se ispostavilo da se „,netehnološki” uslovi više ne mogu uzimati ,zdravo za gotovo".Na primeru širenja vetroturbina jasno se videlo da se do konsenzusa u vezi sa njihovom gradnjom nije lako došlo. Saglasno tome je predložen prvi model socijalne prihvaćenosti koji uključuje javnu, političku i regulativnu prihvaćenost (Carlman,1984).
Socijalna prihvaćenost OIE dobija na značaju u svetlu izraženijeg interesa mnogih zemalja da u bližoj budućnosti intenzivnije koriste svoje geotermalne resurse (Baba, 2015). Geografska znanja, na primer,od pomoći su u studijama socijalne prihvaćenosti alternativnih oblika energije budući da pružaju punije značenje ključnih geografskih pojmova poput mesta, prostora, teritorije ili predela (Fast, 2013). Socijalna prihvaćenost energije iz OIE predstavlja višedimenzionalni teorijski konstrukt (Tabela 1).

Većina autora koristi trokomponentni model socijalne prihvaćenosti koji uključuje:socio-političku prihvaćenost (social-political acceptance); tržišnu prihvaćenost (market acceptance) i lokalnu prihvaćenost (community acceptance) (Wustenhagen et al., 2007). U nekim modelima društvene prihvaćenosti razmatraju se sledeće tri komponente: specifičnosti tehnologije, kontekst (milje) u kome se uvodi, te uključenost stejkholdera (Brohmann et al., 2007).

Tabela 1 - Dimenzije socijalne prihvaćenosti OIE (Wustenhagen et al., 2007)

Table 1 - Dimensions of social acceptance of RES

\begin{tabular}{|l|c|c|}
\hline \multicolumn{3}{|c|}{ Dimenzije prihvaćenosti } \\
\hline Socio-politička & Lokalna & Tržišna \\
\hline Prihvaćenost tehnologije i energetske politike & Proceduralna pravda & Potrošači \\
\hline Široka podrška javnosti & Distributivna pravda & Investitori \\
\hline Podrška stejkholdera & Poverenje & Kompanije \\
\hline Podrška kreatorima energetske strategije & & \\
\hline
\end{tabular}

Težište istraživanja socijalne prihvaćenosti OIE usmerava se prema faktorima za koje se veruje da imaju veliki uticaj u prihvatanju i realizaciji tehnologija zasnovanih na korišćenju OIE. Pažnja se najviše posvećuje političkoj orijentaciji ispitanika, stepenu obrazovanja, visini prihoda, rodu, uzrastu, mestu življenja, vezanosti za mesto, ekološkoj svesti itd. (Musall \& Kuik 2011; Pellizzone et al., 2017). Naučno saznajni cilj se uglavnom odnosi na objašnjenje kako pomenute nezavisne promenljive utiču na znanja, percepcije i stavove ispitanika po pitanju OIE.

Kod istraživanja socijalne prihvaćenosti energije iz OIE tri dimenzije, čini se, imaju najveći značaj: znanje, percepcije i zabrinutost zbog mogućih posledica uvođenja nove tehnologije (Assefa \& Frostell, 2007). Prva dimenzija se odnosi na to šta građani znaju o određenom obliku energije iz obnovljivih izvora; drugom se utvrđuje šta misle i kakve su im preferencije po pitanju različitih OIE. Trećom dimenzijom se zadire u osećanja ispitanika ne bi li se utvrdilo postojanje ili odsustvo zebnje zbog, eventualno ispoljenih, neželjenih efekata rada nekog postrojenja.

\subsection{Socio-politička prihvaćenost OIE /}

Socio-political acceptance of RES

Socio-poliitička prihvaćenost OIE govori o tome u kojoj meri kreatori energetske politike, kao i široka javnost, prihvataju tehnologije OIE što se može kvantitativno utvrditi ispitivanjima različitog tipa. Mek Kormik pod ovom dimenzijom socijalne prihvaćenosti podrazumeva proces u kojem pojedinci (ili organizacije) donose odluke, razrešavaju sukobe, formiraju partnerstva, odgovaraju na vladine mere i angažuju se u javnim poslovima (McCormick, 2007). Politička pitanja su neraskidivo vezana za odnose moći kojom raspolažu akteri u odlučivanju o strategijama razvoja OIE.

Socio-politička prihvaćenost očigledno obezbeđuje stalan i pouzdan institucionalni okvir za uvođenje tehnologija OIE. Volsink, verovatno na osnovu ove postavke, smatra da je prva dimenzija socijalne prihvaćenosti najvažnija budući da utiče na ostale dve (Wolsink, 2013). Uprkos tome što obezbeđenje lokalne podrške ima značaj za projekte usmerene prema lokalnim potrebama, još je važnije prihvatanje nacionalne strategije razvoja OIE. Posledice eventualnog jaza po ovom pitanju mogu se odraziti na usporenje 
pa i odustajanje od ovakvih projekata. Na prostoru jugoistočne Evrope već nekoliko godina stanovnici brojnih ruralnih područja (u Srbiji, Bosni i Hercegovini, Crnoj Gori itd) izražavaju otpor različitog intenziteta prema građenju novih malih hidroelektrana.

\subsection{Tržišna prihvaćenost OIE / Market acceptance of OIE}

Tržišna dimenzija se usredsređuje na to da li je pojedinac (ili neki akter korporativnog sveta) voljan da izdvoji dodatna sredstva da bi ostvario uštede u energiji, te na difuziju novih tehnologija OIE u domaćinstvima i korporacijama. Kod ove dimenzije socijalne prihvaćenosti potrošači igraju različite uloge u zavisnosti od svojih interesa. Korisnici koji će neposredno osetiti korist od uvođenja nekog OIE ispoljiće, po pravilu, privrženost novoj energetskoj tehnologiji ukoliko ona i na tržištu potvrđuje svoju isplativost. Zainteresovani akteri, vođeni tržišnim faktorima, doprinose tehnološkim inovacijama i diversifikaciji u sektoru energije. Ovi akteri na razvoj projekta utiču tehnološki, finansijski i/ili politički (Jacobsson \& Johnson, 2000).

Rodžersova difuziona teorija širenja inovacija prikladna je za objašnjavanje različitih faktora koji utiču i na usvajanje novih tehnologija u oblasti OIE, uključujući i geotermalne vode (Rogers, 2003). Difuzioni proces započinju „inovatori”i „rani usvajači” (adopters), koji čine $15 \%$ od stanovništva koje se izjasnilo za prihvatanje neke inovacije, pre nego što to učini „,rana većina”. Rezultati empirijskih istraživanja ukazuju na to da postoje značajne razlike po pitanju socio-demografskih obeležja između ljudi koji na početku prihvataju uvođenje novih sistema energije iz obnovljivih izvora i ostalog dela zajednice. Pojedinci koji se odlučuju za uvođenje OIE u svoja domaćinstva obično ispoljavaju pojačan interes za pitanja zaštite životne sredine (Schelly, 2014). Inovatore takođe karakteriše viši stepen postignutog obrazovanja (Sigrin et al., 2015), a veće bogatstvo kojim raspolažu omogućava im da prednjače u uvođenju alternativnih oblika rešavanja potreba za energijom (Stedmon et al., 2007; Sigrin et al., 2015).

\subsection{Lokalna prihvaćenost OIE / Local acceptance of OIE}

Treća dimenzija socijalne prihvaćenosti OIE je lokalna kojom se zatvara tzv. trougao socijalne prihvaćenosti, analizira prisutne nedoumice meštana $u$ vezi sa izgradnjom postrojenja za korišćenje OIE i prateće infrastrukture. Kod ove dimenzije u žiži razmatranja nalaze se interesi dve kategorije: meštana i jedinice lokalne samouprave (opština, grad, pokrajina i sl.). Geler je mišljenja da slaba informisanost i obučenost dovode do nedovoljno razvijene svesti o OIE, dobrobiti koja nastaje njihovim korišćenjem i finansijskim mogućnostima (Geller, 2003). Kredibilne informacije više su nego korisne u stvaranju uslova za usvajanje i realizaciju projekata u ovoj oblasti, posebno sa stanovišta potrošača i potencijalnih investitora.

Participacija uključuje različite stejkholdere tokom realizacije nekog projekta. Stepen učešća ljudi u lokalnoj zajednici, na koje se uvođenje novih tehnologija OIE odražava (neposredno ili posredno), obično se nalazi u sredini spektra između dva ekstrema. Prva krajnost jeste pasivna participacija (jednosmerno informisanje građana o toku projekta) i prikupljanje informacija od građana u početnoj fazi realizacije projekta (na primer, anketiranjem). Druga krajnost je interaktivna participacija (recimo, uspostavljanje novih institucija u lokalnoj sredini) i participacija putem samomobilizacije,odnosno kada se meštani odluče da deluju nezavisno od spoljašnjih institucija, nastojeći da menjaju system (Cornwall, 2008). Između pomenutih oblika učešća nalaze se preostala tri oblika: participacija na osnovu konsultacija sa spoljnim izvorima (bez učešća u odlučivanju), participacija po osnovu materijalnih podsticaja, te funkcionalna participacija (posle odluke o projektu).

\section{SOCIJALNA PRIHVAĆENOST GEOTERMALNE ENERGIJE / \\ SOCIAL ACCEPTANCE OF GEOTHERMAL ENERGY}

Literaturni izvori o socijalnoj prihvaćenosti geotermalnih izvora energije još su oskudni, gledano u globalnim razmerama, premda se broj radova iz ove oblasti postepeno uvećava. Sprovode se i istraživanja u kojima se sagledava uloga javnosti i stejkholdera u procesu inovacija u geotermalnom energetskom sektoru, uključujući i geotermalne vode. Socijalni aspekti korišćenja geotermalne energije uglavnom se istražuju kvalitativnim metodama (preko fokus grupa, radionica, interaktivnih konferencija) ili kvantitativnim metodama (najčešće korišćenjem ankete kao istraživačkog instrumenta). Nedavno je primenjen i mešoviti istraživački dizajn (kombinacija kvantitativnog i kvalitativnog metoda) prilikom istraživanja socijalne prihvatljivosti geotermalne energije iz brojnih izvora na prostoru centralne Italije u provinciji Viterbo (Pellizzone et al., 2017). Najviše pažnje, kada je reč o istraživanju prihvaćenosti geotermalne energije u javnosti, zaslužju radovi nastali tokom minule decenije (Dowd et al., 2011; Kubota, 2015; Stauffacher et al., 2015). Dva rada se izdvajaju po tome što se predmet istraživanja odnosio na zastupljenost tema o geotermalnim OIE u masovnim medijima (Stauffacher et al.,2015; Romanach et al., 2015).

Brojne studije pokazuju da OIE, uključujućii geotemalne izvore, postaju sve privlačnija oblast za 
ulaganje u ruralnim, po pravilu, nerazvijenim područjima (Žikić i dr., 2017).

Učešće geotermalnih izvora u proizvodnji obnovljive energije u Srbiji i dalje je skromno, 2014. godine, na primer, iznosilo je svega 0,5\% (Domazet i Kaličanin, 2017). Pitanje integrisanja OIE u elektroenergetski sistem, i tzv. zelenu ekonomiju uopšte, više se ne dovodi u pitanje (Hanić, 2014).

Geotermalne izvore ipak treba promovisati da bi postal privlačniji poput energije vetra ili biomase. $U$ Evropi se, recimo, od 2007. godine obeležava Dan vetra (15. jun). Slično bi se moglo uraditi kad je o geotermalnoj energiji reč. Niskotemperaturne geotermalne vode koriste se za grejanje i slične namene jer prenos vruće vode ili pare iziskuje velika ulaganja, što znači da se takva geotermalna voda mora iskoristiti lokalno. Njen potencijal omogućava balneološko i rekreativno korišćenje da bi se pre svega obezbedila energetska toplifikacija banjskih objekata i za medicinske svrhe (Dragović i dr., 2014).

Peliconi i saradnici su sproveli prvo ispitivanje percepcija stejkholdera i pripadnika lokalne zajednice o mogućnosti korišćenja geotermalnih resursa na prostoru južne Italije (Termini Imerese) na Siciliji (Pellizzone et al., 2015). Dobijeni rezultati ukazuju na to da stavovi o geotermalnim resursima umnogome odražavaju specifične okolnosti vezane za određeno mesto, odnosno kraj. Ispitivanje na jugu Italije je pokazalo da su ispitanici najveće koristi od korišćenja geotermalnih resursa, zbog poslovične nezaposlenosti i slabe industrijske aktivnosti, videli u potencijalnom otvaranju novih radnih mesta. To je presudno uticalo na stavove opšte javnosti, stejkholdera i kreatora energetske politike, uprkos potencijalnoj opasnosti od seizmičke aktivnosti na Siciliji.

Kada su Peliconi i saradnici dve godine kasnije sproveli istraživanje o socijalnoj prihvaćenosti geotermalnih izvora na prostoru centralne Italije, pažnju ispitanika su najviše privlačila tehnička i etička pitanja. Opasnosti od moguće zagađenosti lokalnih voda zbog prisustva arsena, kao i rizik od mikroseizmičke aktivnosti, u velikoj meri su oblikovale percepcije Italijana u ovoj regiji o geotermalnim izvorima (Pellizzone et al., 2017). Autori su utvrdili i slab stepen poverenja u stejkholdere, uključene u ove projekte. Slične percepcije ispitanika o mogućim izvorima zagađenosti vode, usled izgradnje postrojenja za korišćenje geotermalnih resursa, primećene su i u drugim delovima sveta, na primer, u Australiji (Dowd et al., 2011). U Grčkoj, s druge strane, meštani su najviše brinuli zbog mogućeg povećanja zagađenosti vazduha (Polyzou \& Stamataki, 2010).

$\mathrm{Na}$ usvajanje i realizaciju projekata u vezi sa korišćenjem geotermalne energije, poput ostalih OIE, utiču nesumnjivo procesi koji se odvijaju u različitim sferama:u društvu, u svetu tehnologije i unutar vlade. Način na koji se uspostavlja interakcija između ova tri sveta značajno utiče na brzinu promene i prihvaćenost tehnologije. Otuda je neophodno steći razumevanje ova tri sveta te proniknuti $u$ to kako se oni prožimaju (Slika 1). Ključno pitanje glasi, kako Daud i saradnici primećuju, „da li društvo prihvata tehnologiju i kako su s njom povezani rizici percipiranja“ (Dowd et al., 2011).

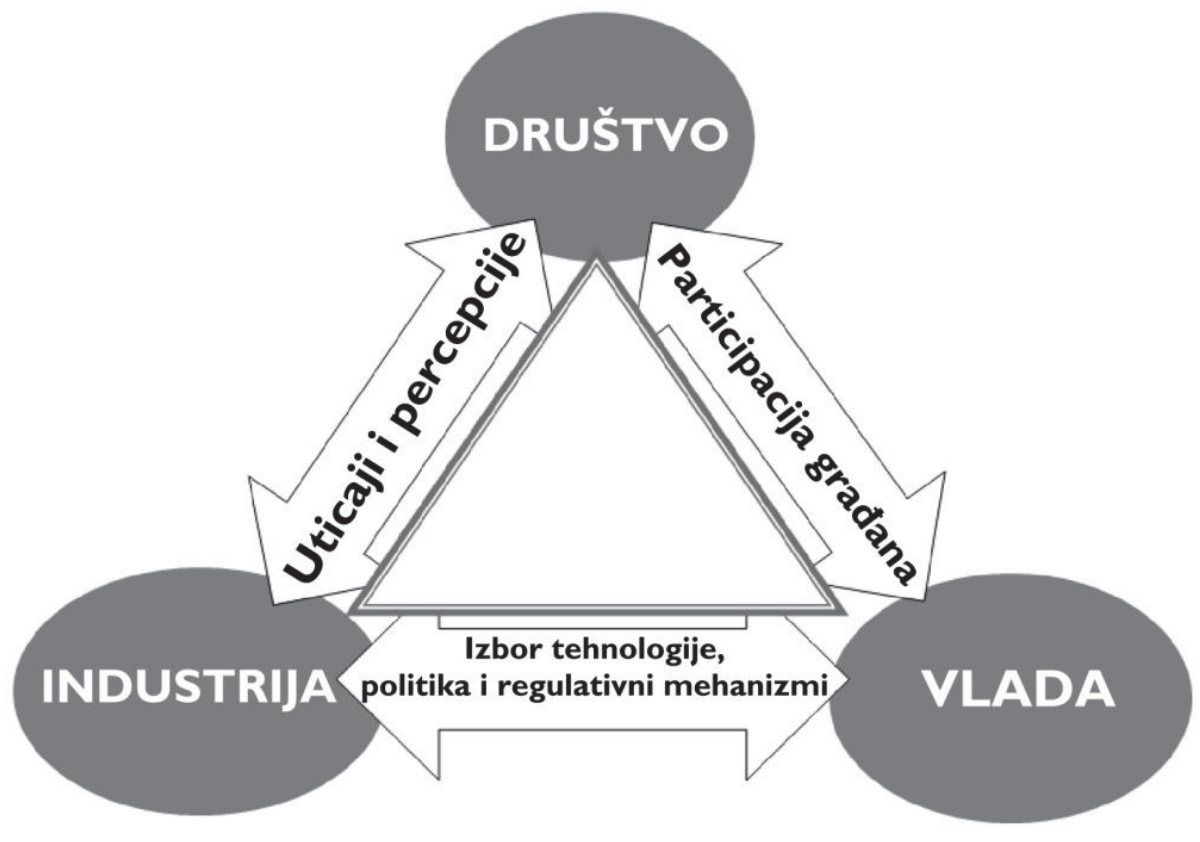

Slika 1 - Prožimanje društva, industrije i vlade (Dowd et al., 2011)

Figure 1 - Mix of society, industry and government 


\section{SOCIJALNA PRIHVAĆENOST OIE U SRBIJI U VREME PANDEMIJE / \\ SOCIAL ACCEPTANCE OF RES IN SERBIA DURING THE PANDEMIC}

Obnovljivi izvori energije mogu da podmire polovinu godišnjih potreba Srbije sa korišćenjem energije biomase, hidropotencijala, sunčeve i energije vetra, te geotermalnih izvora. Sa većom proizvodnjom i razvojem tehnologija, moglo bi se očekivati smanjenje cene što bi doprinelo većoj prihvaćenosti OIE. Pandemija COVID-19 nije prekinula interes za OIE u Srbiji. Javilo se, štaviše, povećano interesovanje za ulaganje u OIE. Na primer, trenutno se u Vranjskoj banji realizuje projekat povezivanja centralnog grejanja korišćenjem geotermalnih voda za zagrevanje domaćinstava preko lokalnog komunalnog preduzeća.

U Srbiji, prema podacima Svetske zdravstvene organizacije (SZO), od posledica zagađenja vazduha godišnje umre oko 6.000 ljudi: dvostruko više nego od oboljenja izazvanih virusom SARS-2. Ako bi se smanjilo ispuštanje ugljendioksida, suspendovanih čestica, te sprovela energetska tranzicija: od termoelektrana na ugalj ka elektranama koje koriste OIE uz podsticaje domaćinstvima da koriste OIE u ruralnim sredinama, a centralno grejanje u gradovima, Srbija bi, poput nekih drugih oblasti, mogla da postane lider Zapadnog Balkana u oblasti korišćenja OIE, odnosno proizvodnje zelene energije.

Nedavno usvajanje Zakona o obnovljivim izvorima energije (2021) trebalo bi da Srbiji olakša put u kretanju ka energetskoj nezavisnosti. Ova zemlja bi, iako se približava cilju od $27 \%$ učešća OIE u proizvodnji energije, trebalo da odustane od politike podsticanja otvaranja malih hidroelektrana (MHE) derivacionog tipa (posebno u zaštićenim područjima), zbog malog udela u ukupnoj proizvodnji električne energije. Nisu zanemarljivi ni protesti lokalnog stanovništva prema MHE u planinskim predelima zemlje, naročito, na Staroj planini koji su učestali upravo u jeku pandemije. Dešavanja oko MHE ukazala su na slabu socijalnu prihvaćenost korišćenja hidropotenicijala planinskih reka za dobijanje struje što je, s druge strane, podstaklo iznalaženje drugiih, prihvatljivijih rešenja. Od 1.januara 2021.godine, na primer, povećana je cena električne energije, pri čemu je pet puta povećana naknada za OIE koju građani plaćaju, kako bi se stvorila povoljnija klima za investiranje u oblasti OIE. Građani su u uslovima pandemije pokazali energetsku, zdravstvenu i ekološku odgovornost i prema svom zdravlju i životnoj sredini, što se pozitivno odražava na socijalnu prihvaćenost OIE.

\section{ZAKLJUČAK / CONCLUSION}

Postojanje obnovljivih izvora u nekom regionu nije dovoljno za njihovo adekvatno iskorišćenje. Ekonomska isplativost, tehnološka izvodljivost i ekološko opterećenje predstavljaju osnovu procene u smislu da li će projekti u oblasti OIE biti opravdani i podržani od korisnika. U zavisnosti od vrste OIE, razlikuju se i problemi sa kojima se suočavaju korisnici, kako međusobno tako i suprotno interesima ulagača, vlasnika ili vlade. Kompenzujući jedne resurse u energetske svrhe zagrevanja ili pristupa električnoj energiji, građani i društvo ne treba da dozvole gubitak važnih civilizacijskih dostignuća: korišćenja čiste pijaće vode, vazduha i obradive zemlje.

Da bi se postigla socijalna prihvaćenost neophodno je da se smanje štetni efekti na životnu sredinu; da se spreče štetne posledice po ljudsko zdravlje; te da se postigne korist za lokalno stanovništvo. Ove ciljeve kod realizacije pojedinačnih projekata u ruralnim oblastima moguće je ostvariti ne samo društvenom inicijativom lokalnog stanovništva (ispostavljanjem zahteva da se poštuju regulativne norme u eksploataciji resursa) već i učešćem u finansijskoj kompenzaciji građana zbog „otimanja” prirodnih resursa. Građani iz različitih delova sveta, u pogledu korišćenja geotermalnih voda,ispoljavali su suprotstavljene stavove oko zagađenja vazduha i voda, do seizmičkih nedoumica, otvaranja radnih mesta i korišćenja u balneološke i turističke svrhe. Podjednako se to odnosi i na uočene razlike između pojedinih regiona, na primer, u Italij. Ovo upućuje na potrebu brižljivijeg sagledavanja interesa različitih stejkholdera u realizaciji bilo kog projekta iz oblasti primene OIE od početne faze (eksplorativnog istraživanja potencijala nekog resursa) do usvajanja i implementacije projekta.

\section{Zahvalnost / Acknowledgement}

Istraživanja predstavljena u ovom radu su urađena uz finansijsku podršku Ministarstva prosvete, nauke i tehnološkog razvoja Republike Srbije, u okviru finansiranja naučno istraživačkog rada na Univerzitetu u Beogradu, Tehničkom fakultetu u Boru, prema ugovoru sa evidencionim brojem 451-039/2021-14/ 200131.

\section{LITERATURA / REFERENCES}

[1] Assefa, G., Frostell, B. (2007), Social sustainability and social acceptance in technology assessment: A case study of energy technologies, Technology in Society, 29(1), pp. 63-78.

[2] Baba, A. (2015), Application of geothermal energy and its environmental problems in Turkey, International Journal of Global Environmental Issues, 14(3/4), pp. 321-331. 
[3] Bidvell, D. (2013), The role of values in public beliefs and attitudes towards commercial wind energy, Energy Policy, 58, pp. 189-199.

[4] Brohmann, B., Feenstra, Y., Heiskanen, E., Hodson, M., Mourik, R., Prasad, G., Raven, R. (2007), Factors influencing the societal acdeptance of new, renewable and energy efficeincy technologies: A Meta-analysis of recent European Projects. European Roundtable for Sustainable Consumption and Production.

[5] Câmpeanu, V., Pencea, S. (2014), Renewable energy sources in Romania: from a "paradise" of investors to a possible abandon or to another boom? The impact of a new pardigm in Romanian energy renewable sources policy, Procedia Economics and Finance, 14, pp. 129-137.

[6] Carlman, I. (1984), The views of politicians and decision-makers on planning for the use of wind power in Sweden. In: European Wind Energy Conference, 22-36 October 1984, Hamburg, pp. 339-343.

[7] Cornwall, A. (2008), Unpacking "participation": Models, meanings and practices, Development Journal, 43(3), pp. 269-283.

[8] Del Rio, P., Burgullio, M. (2009), An empirical analysis of renewable energy development on local sustainability, Renewable and Sustainable Energy Reviews, pp. 1314-1325.

[9] Devine-Wright, P. (2011), Placement attachment and public acceptance of renewable energy: A tidalenergycase study, Journal of Environmental Psychology, 31, pp. 336-343.

[10] Domazet, I., Kaličanin, T. (2017), Analiza resursa u cilju podsticanja proizvodnje energije iz biomase, Ecologica, 24(86), str. 353-358.

[11] Dowd, M., Boughen, N., Asworth, P., CarrCornish, S. (2011), Geothermal energy in Australia: investigating social acceptance, Energy Policy, 39, pp. 6301-6307.

[12] Dragović, Nj., Vuković, M., Štrbac, N. (2014), Održivost korišćenja niskotemperaturnih geotermalnih voda, Ecologica, 21(74), str. 243-248.

[13] Fast, S. (2013), Socal acceptance of renewable energy: Trends, concepts and geographies, Geography Compass, 7(12), pp. 853-866.

[14] Gaede, J., Rowlands, I.H. (2018), Visualizing social acceptance research: A bibliometric review of the social acceptance literature for energy technology and fuels, Energy Research \& Social Science, 40, pp. 142-158.

[15] Geller, H. (2003), Energy revolution: Polices for a sustainable future. Island Press.
[16] Kubota, H. (2015), Social acceptance of geothermal power generation in Japan, Proceedings World Geothermal Congress, Melbourne, Australia, April 19-25.

[17] Gerhinger, M., Loksha, V. (2012), Geothermal handbook: Planning and inancing Power Generation, Washington, USA: World Bank.

[18] Hall, S., Foxon, T.J., Bolton, R. (2016), Financing the civic energy sector: How financial institutions affectownership models in Germany and the United Kingdom, Energy Research and Social Science, 12, pp. 5-15, 2016.

[19] Hanić, A., Baranenko, E. (2014), Zelena ekonomija - uticaj energije vetra na ekonomiju, Ecologica, 21(74), str. 129-134.

[20] Hicks, J., Ison, N. (2011), Community-owned renewable energy (CRE): Opportunities for Australia, Rural Society, pp. 244-255.

[21] Jacobsson, S., Johnson, A. (2000), The diffusion of renewable energy technology: an analytical framework and key issues for research, Energy Policy, 28, pp. 625-640.

[22] McCormick, K. (2007), Advancing bioenergy in Europe: Exploring bioenergy systems and sociopolitical issues (doctoral dissertation), IIIEE, Lunds University, Sweeden.

[23] Musall, F.D., Kuik, O. (2011), Local acceptance of renewable energy - A case study from southeast Germany, Energy Policy, 39(6), pp. 3252-3260.

[24] Pellizzone, A., Allansdottir, A., De Franco. R., Muttoni, Manzella. A. (2015), Exploring public engagement with geothermal energy in southern Italy: A case study, Energy Policy, 85, pp. 1-11.

[25] Pellizzone, A., Allansdottir, A., De Franco. R., Muttoni, Manzella. A. (2017), Geothermal energy and the public: A case study on deliberative citizens' engagement in central Italy, Energy Policy, 101, pp. 561-570.

[26] Polyzou, O., Stamataki, S. (2010), Geothermal energy and local societies, A NIMBY Sindrome Contradiction? World Geothermal Congress, Bali, Indonesia, April 25-19.

[27] Rogers, E.M. (2003), Diffusion of innovations (5th edition). New York, Free Press.

[28] Romanach, L., Carr-Cornish, S., Muriuki, G. (2015), Societal acceptance of an emerging energy technology: how is geothermal energy portrayed in Austrailian media? Renew, Sustain. Energy Rev., 42, pp. 1143-1150.

[29] Schelly, C. (2014), Implementing renewable energy portfilio standards: The good, the bad, and 
the ugly in a two state comparison, Energy Policy, 67, pp. 543-551.

[30] Sigrin, B., Pless, J., Drury, E. (2015), Diffusion into new market: evolving custormer segments in the solar photovoltaics market, Environmental Research Letters, 10, pp. 84001-84008.

[31] Stauffacher, M., Muggli, N., Scolobig, A., Moser, C. (2015), Framing deep geothermal energy in mass media: the case of Switzerland, Technol. Forecast. Soc. Change, 98, pp. 60-70.

[32] Stedmon, A.W., Winslow, R., Langley, A. (2007), Micro-generation schemes: user behaviours and attitudes towards energy consumption, Ergonomics, 56, pp. 440-450.

[33] Šahović, N., Pereira da Silva, P. (2016), Community renewable energy - Research perspectives, Energy Procedia, 106, pp. 46-58.

[34] UNDP, https://www.rs.undp.org/content/serbia/sr /home/sustainable-development-goals.html, pristup dana 4.2.2021.

[35] Upham, P., Oltra, C., Boso, À. (2015), Towards a cross-paradigmatic framework of the social acceptance of energy systems, Energy Research \& Social Science, 8, pp. 100-112.

[36] Viardot, E. (2013), The role of cooperatives in overcoming the barriers in adoptin of renewable energy, Energy Policy. 63, pp. 756-764.
[37] Warren, C.R., McFadyen, M. (2010), Does community ownership affect public attitudes to wind energy? A case study from south-west Scotland, Land Use Policy, 27(2), pp. 204-213.

[38] Witter, J.B., Trainor-Guitton, W.J., Siler, D.L. (2019), Uncertainty and risk evaluation during the exploration stage of geothermal development: A review, Geothermics, 78, pp. 233-242.

[39] Wolsink, M. (2013), Fair distribution of powergeneration capacity: justice, microgrids, and utilizing the common pool of renewable energy. In: Bickerstaff, K., Walker, G. \& Bulkeley, H. (eds.) Energy justice in a changing climate: social equity and low carbon energy.

[40] Wolsink, M. (2000), Wind power and the NIMBYmyth: institutional capacity and the limited significance of public support, Renewable Energy, 21, pp. 49-64.

[41] Wustenhagen, R., Wolskink, M., Burer, M.J. (2007), Social acceptance of renewable energy innovation: an introduction to the concept, Energy Policy, 35(5), pp. 2683-2691.

[42] Žikić, S., Paunković, J., Jovanović, V. (2017), Značaj obnovljive energije za održivi regionalni razvoj Republike Srbije, Ecologica, 24(86), str. 348-353. 